\title{
СИНКРЕТИЧЕСКИЙ ПОДХОД К ПРОБЛЕМАМ ИНСТРУМЕНТАЛЬНО-ИСПОЛНИТЕЛЬСКОЙ ПОДГОТОВКИ ПЕДАГОГА-МУЗЫКАНТА В ВУЗЕ
}

\section{THE SYNCRETIC APPROACH TO THE PROBLEMS OF INSTRUMENTAL INTERPRETATIVE PREPARATION OF A MUSIC TEACHER AT THE UNIVERSITY \\ I. Aranovskaya G. Dvoynina \\ G. Sibiryakova}

Summary: The syncretic approach is regarded as a necessary factor of the modern instrumental interpretative preparation of a music teacher at the university, which provides the orientation at the development of ability to invent and combinate the material, and the necessity to explore pedagogical objects in course of the search of a single basement in culture. We detect the problems and contradictions that prevent the realization of the syncretic approach in the process of studying the instrumental interpretation of a music teacher at the university. We justify the terms due to which the syncretic approach to the instrumental interpretative preparation of a music teacher at the university creates a new form of communication with music and allows to build the pedagogical process as an artistic and basically syncretic act.

Keywords: syncretism, information base of instrumental interpretation, content of studying the instrumental interpretation, instrumental interpretation of a music teacher, music lesson as an art lesson, pedagogical music activity as an open system.
$\mathrm{Y}$ рок музыки как урок искусства призван генерировать художественное творчество средствами музыки, и, поэтому, обладает творческой, художественной функцией. Значительную роль в процессе становления урока музыки как урока искусства играет инструментально-исполнительская деятельность педагога-музыканта. Известно, что данная деятельность разнообразна и требует особого синкретического (целостного) типа мышления, направленного на раскрытие художественного образа произведения выразительными средствами звуков, организованных особым образом - по высоте, метроритму, динамике. Виды инструментального исполнительства, которые используются на уроках музыки (сольное исполнение, аккомпанирование пению учащихся, разучивание партий под инструмент, чтение с
Арановская Ирина Владленовна

Д.n.н., профессор, ФГБОУВО «Волгоградский государственный социально-педагогический университет» aalu@yandex.ru

Двойнина Галина Борисовна К.п.н., дочент, ФГБОУ ВО «Волгоградский государственный социально-педагогический университет» madam.dvoynina2010@yandex.ru

Сибирякова Галина Георгиевна

К.n.н., nрофрессор, ФГБОУВО «Волгоградский государственный сочиально-педагогический университет»

ib-610@yandex.ru

Аннотация: Синкретический подход рассматривается как необходимый фактор современной практики инструментально-исполнительской подготовки педагога-музыканта в вузе, обеспечивающий ориентацию на развитие способности изобретения и комбинирования материала, потребность исследовать педагогические объекты в направлении поиска единого основания в культуре. Выявлены проблемы и противоречия, препятствующие реализации синкретического подхода в процессе вузовского обучения педагога-музыканта инструментальному исполнительству. Обоснованы условия, при которых синкретический подход к инструментально - исполнительской подготовке педагога-музыканта в вузе, создавая новый формат общения с музыкой, позволяет построить педагогический процесс как творческий акт, синкретичный по своей сути.

Ключевые слова: синкретизм, информационная база инструментального исполнительства, содержание обучения инструментальному исполнительству, инструментальное исполнительство педагога-музыканта, урок музыки как урок искусства, музыкально-педагогическая деятельность как открытая система.

листа, проигрывание мотивов из популярных произведений, подбор по слуху, транспонирование и др.) входят в контекст изучаемой школьной программы. Сочетание в музыкально-педагогической практике этих видов деятельности может комбинироваться педагогом и служить общей цели - созданию урока искусства с помощью музыкального инструмента.

Однако, в современной школьной практике обучения музыке инструментально-исполнительская деятельность используется педагогами-музыкантами недостаточно часто, не смотря на то, что обучение навыкам владения музыкальным инструментом составляет основу их профессиональной подготовки в вузе. Поэтому формирование у будущих педагогов-музыкантов по- 
требности в постоянном применении полученных инструментально-исполнительских навыков является важнейшей задачей их профессионального обучения.

Сочетание художественных и нехудожественных видов деятельности в инструментально-исполнительской практике, диффузность её границ, миграция одного вида в другой ставят перед педагогом-музыкантом сложные задачи, связанные с постоянным изменением формата инструментального исполнительства, требуют понимания основного звена данного процесса, от которого зависит подбор тех или иных педагогических приёмов. Изменчивость и многовариантность современных форм инструментального исполнительства обусловили его отнесение к явлениям синкретическим, а также - целесообразность изучения проблем инструментально-исполнительской подготовки педагога-музыканта с точки зрения синкретического подхода.

Мировоззрение педагога-музыканта, его ценностное отношение к искусству, стремление к творчеству через постоянное самообразование и саморазвитие, аккумулируются в его инструментально-исполнительской деятельности и генерируют «вычленение художественного начала из первоначального синкретического комплекса и превращение этого начала в первоначальный способ творчества» [10;с. 210].

Интенсивность творческого процесса и воздействие на учащихся исполненной педагогом музыки напрямую зависит не только от исполнительского, но и от других видов его опыта, от его умения производить на основе данного опыта многочисленные действия, включающие в педагогический процесс произведения других видов искусства. Рождение музыкального образа как центра, от которого далее расходятся смыслы, представляет собой «творческую комбинирующую деятельность», которая «оказывается в непосредственной зависимости от других форм нашей деятельности, и в частности, от накопления опыта» [7; с. 5].

В настоящее время в практике преподавания дисциплины «Музыка» в средней школе академическое инструментальное исполнительство педагога представлено недостаточно. Несмотря на то, что компьютер и интернет прочно вошли в школьную музыкально-педагогическую практику (появилась возможность прослушать любое инструментальное произведение в интернете, обеспечить исполнение вокальных произведений учениками под «минус», который выполняет функции концертмейстера), этим нельзя заменить собственное инструментальное исполнительство педагога, его аккомпанирование пению учеников, инструментальную поддержку вокальных партий, которые поют ученики и многое другое. Не случайно Д.Б. Кабалевский подчеркивал: «Из всех умений, которыми должен обладать учитель музыки, надо выделить владение инструментом. Без механической записи на уроке музыки, конечно, не обойтись, особенно когда в классе должен прозвучать хор, оркестр, оперная сцена и т.п., но она должна быть дополнением к живому исполнению учителя, а не заменой его. Это очень важно, по крайней мере, с трех точек зрения: во-первых, живое исполнение всегда создает в классе более эмоциональную атмосферу; во-вторых, при живом исполнении учитель может, если надо, остановиться в любой момент, повторить любой эпизод, даже отдельный такт, вернуться к началу и т.д.; в-третьих, учитель, играющий на музыкальном инструменте, служит хорошим примером для своих питомцев, показывая на практике, как важно и интересно самому уметь исполнять музыку» [9; с. 35]. Б.В. Асафьев также пишет о том, что исполнительский опыт, игра на инструменте дают «ощущение материала изнутри» [5;с.23], интенсифицируют осмысление музыки, обеспечивают корреляцию музыкальной и вербальной речи.

Здесь необходимо отметить следующее. Подобно тому, как в процессе работы над музыкальным произведением его художественный образ диктует исполнителю выбор приёмов игры, качество и уровень динамики, построение кульминаций, так и художественные задачи, решаемые в процессе исполнения того или иного произведения педагогом - музыкантом на уроках, подсказывают ему пути решения, собственно, педагогических задач в области передачи смыслов музыки, её ценности учащимся. При этом, для создания наиболее убедительной интерпретации инструментального произведения, педагог-музыкант часто оперирует средствами художественной выразительности из разных видов искусств: литературы, театра, живописи, кино, мультимедийных технологий и т.д. Это, в свою очередь, требует наличия у будущего педагога-музыканта более широкого спектра знаний, такого музыкально-эстетического тезауруса, который представляет собой «результат и процесс субъектной организации знания соответственно функции учителя музыки в пространстве современного образования и культуры. Это ресурс, позволяющий развивать реальность, менять её; развивать свои внутренние потенциалы» [11; с. 382].

Данный тезаурус, безусловно, должен включать в себя широкую осведомлённость в других видах искусства, а также в других областях знания, связанных, например, с компьютерными технологиями. Таким образом, речь идёт о формировании не узкопрофессиональных знаний современного педагога-музыканта, а знаний более широких, отвечающих более высокому уровню его эрудиции, интеллекта, общей культуры. Инструментальное исполнительство выступает здесь драйвером роста, платформой, на которой появляются новые знания, обусловленные художественно-педагогической задачей передачи смыслов музыки ученикам. 
Не случайно поиск путей совершенствования инструментально-исполнительской подготовки педагогов-музыкантов в вузе в настоящее время широко представлен в трудах М.А. Антоновой, Н.А. Вогралик, Г.Н. Курбоновой, Т.Е. Мариупольской, Т.Ю. Усачёвой и других. Авторы подчёркивают огромную роль инструментального исполнительства в практике общего музыкального образования, при этом ряд исследователей опирается на синкретический подход в изучении явлений искусства, который позволяет рассматривать с точки зрения целостности и единства многих качеств и факторов профессиональную подготовку будущего педагога-музыканта.

Так, например, Т.Г. Мариупольская подчеркивает: «синкретизм XX и XXI века в связи с невиданным научнотехническим прогрессом породил неизвестные до той поры, синтетические виды искусства - кино, телевидение, а также современные интерактивные средства культурной коммуникации. Кроме того, идея синкретизма как представление об универсальности и единстве искусства, привлекавшая к себе внимание многих педагогов, теоретиков и практиков искусства, стала, особенно в последнее время, одной из главных, доминирующих идей в деятельности музыкантов, художников, писателей, режиссеров, видящих в этой традиционной и вместе с тем новаторской идее пути обогащения и обновления всего спектра художественно-выразительных средств, а также способы расширения эстетического кругозора человека» $[13 ;$ с. 8$]$.

Синкретический подход характеризует педагогический процесс на уроке искусства как единство рационального и чувственного, выступает особым универсальным качеством данного процесса, содействует поиску нестандартных решений его проблем. Данный подход предполагает «органичное соединение элементов и структур культурной реальности, основанное на принципе связи и имеющее единые первородные корни, но при этом каждое составляющее этого соединения имеет возможность дальнейшего обособления и самостоятельного существования» [4;с. 7].

В современной науке синкретизм (от греч. «соединение») как метод применяется для описания несопоставимых, часто антагонистических взглядов, образующих в результате условное единство. Несмотря на то, что данное понятие используется достаточно широко, сохраняется основное качество синкретизма -нерасчленённость, или условная делимость сложного явления на простые компоненты. При этом, согласно теории синкретизма, синкретическая система относится к типу открытых систем и развивается в любой ее точке.

Что касается педагогики, то, по утверждению Т.Г. Мариупольской, «в любом случае каждая традиционная педагогическая система, если она не утратила своей жизнеспособности и действенности, является системой формально не завершенной, «разомкнутой»; она постоянно эволюционирует, хотя и с неодинаковой интенсивностью, в различных своих «узлах», звеньях, уровнях, что и служит гарантией ее самосохранения»[13; с 9].

Педагогическая деятельность, к которой вуз готовит будущего педагога-музыканта, является открытой системой, она взаимодействует с окружающей ее средой во многих аспектах: образовательном, воспитательном, культурном, информационном и т.д. Передача смыслов музыкального произведения происходит через чувства и эмоции, через рождение художественного образа в звуках. Данный процесс стимулируется взаимосвязями с другими видами искусства и областями деятельности. Чем богаче жизненный и исполнительский опыт педагога-музыканта, тем более яркие образы он сможет создать в процессе исполнения, тем выше эффективность художественного освоения этих образов учащимися. Сказанное позволяет говорить о том, что сама система подготовки педагога-музыканта является сложноструктурированной, многомерной, открытой системой, которая в настоящее время особенно «устремлена на синтез с другими формами познания мира человеком» [8; с. 123]. Данная позиция характеризует потребность исследовать педагогические объекты в направлении поиска «единого основания в культуре, которая не должна быть разделена на материальную и духовную» [8; с. 125].

А.С. Соколов рассматривает два вида синкретизма: один - «естественный», включающий педагогические методы, в том числе, применяемые на начальном этапе обучения музыке; второй - «искусственный», под которым понимается особое творческое состояние, включающее разнонаправленные методы и приёмы из других профессиональных отраслей как искусства, так и науки и техники [14; с. 207].

Н.Н. Телышева понимает под синкретизмом объединение «закреплённых форм сознания, мышления» которые сохраняются «не только как объекты в произведениях искусства, философии, но и в общественном поведении, соответствующем определённому способу мышления в тот или иной исторический период, частными средствами и инструментами которого как раз и являются искусство и образование» [15; с. 76]. Таким образом, синкретический подход, с точки зрения Н.Н. Телышевой, заключён, прежде всего, в единстве двух сфер деятельности человека: искусства и образования. Однако, существующая оторванность двух этих сфер в педагогической практике приводит к тому, что «в результате теряются закономерности развития и образования, и искусства, а отдельные концепты рассматриваются разрозненно, как несоизмеримые профессионально-технические явления, между которыми нет общих сторон, непосредственно данных чувственному опыту» [15; с. 75]. 
Анализируя детское творчество, Л.С. Выготский, рассматривает синкретизм игры ребёнка как целостное явление, которое «указывает на тот общий корень, из которого разъединились все отдельные виды детского искусства» [7; с.48]. Выготский подчёркивает, что, после отделения друг от друга, эти новые виды не являются обособленными и «охотно впитывают в себя и вбирают элементы других видов» [7;с. 48]. В связи с этим очевидно, что важнейшей линией обучения будущих педагоговмузыкантов в вузе является ориентация их профессиональной подготовки на ведущую роль синкретического подхода к инструментальному исполнительству на уроках музыки в школе.

Как уже было отмечено, художественность и эмоциональность исполнения определяется умением педагога-музыканта создать убедительную для себя и учеников интерпретацию произведения, в основе которой - художественный образ, созданный с помощью словесных описаний, навеянный прозой, поэзией, произведениями живописи. Следовательно, создание исполнительского художественного образа требует от педагога-музыканта умения вызвать нужные ассоциации с помощью вербальных действий, использовать художественное содержание произведений из других сфер искусства. Большие возможности открывают здесь перед педагогом-музыкантом компьютерные технологии, с помощью которых он может инструментовать фрагмент симфонического произведения, проиграть ученикам наиболее яркие мотивы, показать звучание разных партий и т.д.[2;с.21] Варианты, в которых педагог-музыкант может применять инструментальное исполнительство, бесконечны. Не случайно Т.Г. Мариупольская подчёркивает: «выполняя функции проводника подрастающего поколения в необъятный мир звуков, учитель музыки должен не только свободно владеть мультимедийными технологиями, облегчающими виртуальный доступ практически ко всем ценностям мировой культуры, но и быть способным в своём собственном исполнении, непосредственно контактируя со своими учениками, познакомить их с лучшими образцами музыкального искусства» [12; с.142].

Таким образом, очевидно, что только собственное исполнительство педагога-музыканта помогает его ученикам понять музыку и полноценно освоить ее художественное содержание. Мы согласны с Н.А. Вогралик, которая подчеркивает: «музыкальная мысль наполняется в процессе собственного исполнения подлинно творческим содержанием. Впечатления, полученные путём собственного исполнительства, собственной практики, несомненно, являются более личностными, субъективно-конкретными, что действенно способствует развитию музыкально-художественного мышления. Не требует особых доказательств ясная истина - эмпирическая база, безусловно, незаменима какими-либо пассивными видами деятельности» [6; с.141].
Музыка в собственном исполнении важна как для учеников, так и для самого педагога-музыканта. В процессе работы над инструментальным произведением и его исполнения происходит осмысление фраз и мотивов через интонацию, как основу природы музыки. Проявляется взаимосвязь музыкальной и вербальной интонаций, слово содействует формированию навыков осмысления музыки учащимися. Универсальный язык музыки содержит в себе необходимые побуждения, символы, логику развёртывания, план действий, стимулы для мышления [3; с. 36].

Художественный образ произведения ясно даёт понимание того, какие средства и приёмы необходимы для его воплощения, определяет связь между художественными средствами, содержащимися в произведениях искусства с «исходными данными»- мировоззрением и мышлением, т. е. теми актами, результатом которых является то или иное сочетание тонов, цвета, тембра и т.д.» [15; с. 75]. Потребность объяснения художественного образа словами, составления текстовой программы произведения или его фрагмента содействует подбору приёмов игры, связывает мысль об исполнении с будущим исполнением. Поскольку «принято считать, что методами обучения занимается педагогика, мировоззрением и мышлением - философия, а искусствоведение - категориями видения и слышания, будто можно видеть и слышать, не мысля, не различая и не связывая элементы поля зрения и слуха» [15; с. 75], постольку вербальная интерпретации обеспечивает фундамент для инструментальной интерпретации, содействует воплощению музыкальной мысли, созданию целостного образа и его эмоциональной передаче.

Поиск ассоциаций в других видах искусства позволяет педагогу-музыканту находить эмоционально более яркие произведения, что, в свою очередь, расширяет сферу его инструментального исполнительства. Мы согласны с М.А. Антоновой в том, что при этом «не вполне решена проблема предметной замкнутости, обусловленной вековыми традициями преподавания исполнительских дисциплин в специальных учебных заведениях» $[1 ;$ с.3].

Решение проблемы «предметной замкнутости» в практике подготовки педагога-музыканта в вузе возможно на основе взаимопроникновения смежных дисциплин. Не случайно, педагоги разрабатывают уроки музыки в разных жанрах: урок-спектакль, урок-концерт, урок-дискотека и др., поскольку современная педагогическая реальность требует от педагога-музыканта, говоря словами Б.В. Асафьева, «способности изобретения и комбинирования материала». Однако, начало такого комбинирования и создания музыкальной модели находятся в исполнительской версии педагога, озвученной непосредственно на инструменте. При таком подходе 
востребована универсальность умений и навыков педагога-музыканта, которая включает исполнительский профессионализм, фантазию художника, предвидение педагога, мудрость воспитателя и интуицию учёногоисследователя одновременно. В данном ракурсе современные требования к инструментально-исполнительской подготовке в вузе должны быть направлены, прежде всего, на формирование у педагога-музыканта стремления к активизации исполнительства в собственной музыкально-педагогической практике.

Известно, что содержание инструментально-исполнительской подготовки будущего педагога-музыканта в вузе включает ряд дисциплин, вооружающих их специальными умениями и навыками, однако «традиционные представления о содержании музыкально-исполнительского обучения входят также в противоречие со спецификой профессиональной подготовки учителя музыки в школе, включающей готовность к использованию в самостоятельной практической работе активных форм и методов, которые вовлекали бы учеников в ролевые игры, решение задач творческого характера» [1; с.3].

Условием исполнительской активности педагога-музыканта в его будущей профессиональной деятельности в школе является создание в процессе инструментально-исполнительской подготовки в вузе таких педагогических условий, в которых центром выступает музыкальное произведение, его образное содержание. Связь художественного образа с современной реальностью, осмысление идей, воплощенных в лучших образцах инструментальной музыки, являются основой формирования потребности педагога-музыканта в расширении информационной базы собственного инструментального исполнительства (слушательских представлений, жанровых, стилистических, репертуарных знаний), ценностного отношения к инструментальному исполнительству и профессии педагога-музыканта в целом. Особая роль здесь отводится преподавателю вуза, который определяет тактику и стратегию инструментально-исполнительской подготовки будущего педагога-музыканта. Таким образом, на первый план в учебном процессе выдвигается совместная музыкально-творческая деятельность педагога и обучаемого.

В настоящее время условия работы педагога-музыканта подвержены значительным изменениям, поэтому он должен быть готов действовать в стремительно изменяющейся реальности. Очевидно, что, с одной стороны, предмет «Музыка» в школе по рейтингу значимости стоит практически на последнем месте, но, с другой стороны, известно, что почти каждый учащийся имеющий смартфон, часто прослушивает темы, фрагменты, мотивы классических произведений известных композиторов. Поэтому в практике музыкального образования в школе необычайно востребовано исполнение на фортепиано небольших музыкальных фрагментов, адаптированных под технические возможности педагога и восприятие учащихся. Такое исполнение предполагает оснащение будущего педагога-музыканта достаточным репертуаром, состоящим из небольших, наиболее популярных фрагментов известных классических произведений, соединение их в попурри, проигрывание в упрощённом изложении. Данный исполнительский навык должен воспитываться постоянно, а репертуар -пополняться новыми фрагментами, которые могут соединяться с разной по характеру музыкой, звучать на фоне поэтической декламации и демонстрации произведений живописи. Таким образом, классические произведения, известные в традиционном исполнении симфонических оркестров, пианистов, скрипачей и др., переходят в «новый формат». Кроме того, фортепиано как универсальный инструмент, может использоваться для переложения популярной эстрадной музыки разных стилей и жанров. Соединение в воображении педагога-музыканта мелодий, тем, фрагментов разностилевой, разножанровой, разновременной музыки создаёт новый, уникальный музыкальный продукт, который помещает трактовку общечеловеческих идей и вечных ценностей в новую форму. Возникает новая «модель мира разорванных связей и хаоса» [14; с. 247], когда синкретический объект распадается на условные компоненты и объединяется вновь, используя компоненты обновлённые.

Следует согласиться с мнением А.С. Соколова, который подчеркивает: «предметом обсуждения в таких случаях должен быть уже не музыкальный текст (его не существует), а коллективный творческий акт, действо, достигающее или не достигающее в силу ряда обстоятельств поставленной цели - духовного слияния с «универсумом». Концепция «интуитивной музыки» устраняет практически все привычные категории, относимые к музыке, вплоть до самой категории «искусство». Она претендует на синкретическую целостность мировосприятия, но сталкивается с необходимостью искусственно стимулировать эту целостность» [14; с. 254]. Такая «целостность мировосприятия» педагога-музыканта позволяет ему ставить и решать педагогические задачи, среди которых в настоящее время важнейшей выступает взаимосвязь музыки как вида искусства и вида человеческой деятельности со всеми сторонами жизни человека. Данное понимание принципиально меняет отношение к содержанию и методам работы педагога-музыканта.

Вышеизложенное позволяет сделать ряд выводов. Очевидно, что явления и процессы окружающей реальности в целом и, в частности, реальности музыкально-педагогической, подвержены чрезвычайной глобализации, а интеграционные движения приводят к объединению разных по своему содержанию форм, связей и отношений. Методы исследования таких явлений также изменяются. Поэтому синкретизм «сегодня высту- 
пает одним из возможных способов анализа культурной реальности» 4 ; с.3], «основой метода педагогики» (А.С. Соколов). Педагогический процесс урока искусства, рассматриваемый как творческий акт, синкретичен по сути. В этой связи инструментально-исполнительская подготовка педагога-музыканта в вузе должна объединять большое количество направлений исполнительства, в которых педагог-музыкант реализуется как солист, композитор, аранжировщик, хормейстер, концертмейстер и др., применяя и комбинируя виды исполнительства в зависимости от собственного «видения» художественного содержания произведения. Образ, родившийся в сознании педагога-музыканта, распадается на условные компоненты, которые обогащаются другими видами исполнительской и межпредметной деятельности, синтезируются и представляют новый вид образа, передавае- мого учащимся. Это позволяет говорить о том, что такая последовательность как «синкерзиз - синтез -синкрезис» является формулой действия принципа «искусственного синкретизма» (А.С. Соколов), актуального в настоящее время в музыкально- педагогической практике.

Следовательно, синкретический подход позволяет взглянуть на проблемы инструментально-исполнительской подготовки педагога-музыканта в вузе в ином ракурсе. Такая подготовка должна быть построена на принципах единства художественного мира музыки и физической реальности. Именно это единство обеспечивает синкретический подход, стирающий границы между музыкальным текстом и педагогической реальностью, а также обуславливающий существование общего контекста творчества педагога-музыканта и учащихся.

\section{ЛИТЕРАТУРА}

1. М.А. Антонова. Педагогические условия подготовки учителей музыки в классе основного музыкального инструмента: на материале занятий фортепианным ансамблем: автореферат дис... кандидата педагогических наук: 13.00.02/ Антонова Марина Александровна; [Место защиты: - Моск. гор. пед. ун-т].- Москва, 2008.-24 с.

2. Арановская И. В., Двойнина Г. Б., Сибирякова Г. Г. Роль информационно-компьютерных технологий в современной практике инструментально-исполнительской подготовки педагогов-музыкантов в ВУзе // Современная наука: актуальные проблемы теории и практики. Серия «Гуманитарные науки» -2019.- №8-2.-С. 21-27.

3. Арановская И. В., Двойнина Г. Б. Инновационные процессы в современном высшем музыкально-педагогическом образовании: теоретические подходы и технологии обучения // Современная наука: актуальные проблемы теории и практики. Серия «Гуманитарные науки» - 2018.-№5-2.- С. 31-36.

4. Архипова Ю. В. Синкретизм в структуре культуры : автореферат дис. ... кандидата философских наук : 09.00.13 / Сарат. гос. ун-т им. Н.Г. Чернышевского. - Саратов, 2005. - 18 C.

5. Асафьев Б. В. Избранные статьи о музыкальном просвещении и образовании.- М.; Л.: Музыка. 1965. -161с.

6. Вогралик Н. А. Игра на фортепиано как необходимый компонент музыкального образования/Н. А. Вогралик //Вестник музыкальной науки.- 2018.- № 4(22).- С.140-144 (эл. ресурс: https://cyberleninka.ru/article/n/igra-na-fortepiano-kak-neobhodimyy-komponent-muzykalnogo-obrazovaniya/viewer).

7. Выготский Л. С. Воображение и творчество в детском возрасте/Л. С. Выготский.-СПб.-1997. (Эл. Ресурс: https://docviewer.yandex.ru/view/87180631/?page).

8. Гутова С. Г. Методологический синкретизм в научных и философских системах/С. Г. Гутова//Контекст и рефлексия: философия о мире и человеке.-2017. Т 6.- № 5А.- С.123-132.(Эл. Ресурс: https://docviewer.yandex.ru/view/87180631/?page).

9. Кабалевский, Д. Б. Воспитание ума и сердца [Текст]: книга для учителя/Д. Б. Кабалевский. - 2-е изд., испр. и доп. - М.:Просвещение, 1984. - 206с.

10. Каган М. С. Морфология искусства. Морфология искусства. Историко-теоретическое исследование внутреннего строения мира искусств. - Ленинград, 1972. - 440c.

11. Калинина Л.Ю. Музыкально-эстетический тезаурус современного учителя музыки: структура и лакуны./Л. Ю. Калинина//European Social Science Journal.Издательство: Автономная некоммерческая организация «Международный исследовательский институт» (Москва).- 2017.- № 11.- С. $382-388$.

12. Мариупольская Т. Г. Исполнительская подготовка будущего учителя музыки. Проблемы и перспективы/ Мариупольская Т. Г. //Наука и школа.- 2017.№1.- С. 141-145 (Эл. Ресурс: https://cyberleninka.ru/article/n).

13. Мариупольская Т. Г. К вопросу о взаимосвязи традиций и новаторства в педагогике искусства/ Т. Г. Мариупольская // ПЕДАГОГИКА ИСКУССТВА.- 2015 г.№4. С. 6-9 (Эл. Ресурс: http://www.art-education.ru/electronic-journal ).

14. Соколов А.С. Музыкальная композиция XX века. Диалектика творчества. Исследование. / А. С. Соколов. - М.: Изд-во «Композитор», 2007 г. - 272 с. 15. Телышева Н. Н. Аудиовизуальный синкретизм в истории искусства и образования/ Н. Н. Телышева //Образование и наука. -2014.-№ 1 (110).- С. $73-89$.

(c) Арановская Ирина Владленовна (aalu@yandex.ru), Двойнина Галина Борисовна (madam.dvoynina2010@yandex.ru), сибирякова Галина Георгиевна (ib-610@уandex.ru)

Журнал «Современная наука: актуальные проблемы теории и практики» 